\title{
ASSESS PREDIABETES RISK, AS A GOLDEN PERIOD FOR PREVENTION OF DIABETES
}

\author{
ICHE ANDRIYANI LIBERTY ${ }^{1 *}$, NASRIN KODIM²
}

${ }^{1}$ Department of Public Health and Community Medicine, Medical Faculty of Sriwijaya University, Palembang, Indonesia. ${ }^{2}$ Department of Epidemiology, Public Health Faculty of Universitas Indonesia, Depok, Indonesia. Email: iche.aliberty@gmail.com

Received: 01 March 2017, Revised and Accepted: 31 March 2017

ABSTRACT

Objective: Prediabetes is a high-risk condition for diabetes development and several other health outcomes later in life, but little is known about the factors associated with this condition. On the other hand, by predicting the risk of prediabetes, it is also a golden period for prevent or delay the diabetes conversion. The aim here was to assess the prevalence, risk factor that associated, and build a model to assess prediabetes risk.

Methods: A cross-sectional study was conducted in Palembang, Indonesia. Data were collected during January until May 2016. We recruited adult age $>15$ years from 16 districts in Palembang. Anthropometric, demographic, and clinical history data were measured by standard methods. Capillary blood glucose was measured by finger prick test, followed by confirmatory oral glucose tolerance tests.

Results: Of a total of 1241 participants, the prevalence of prediabetes was $27.8 \%$ (345 participants) and $72.2 \%$ (896 participants) and those were normal blood glucose. Employment, age, exercise, alcohol consumption, body mass index, systolic pressure, diastolic pressure, waist circumference, and hypercholesterol history were screened out as independent factors to build the prediction risk model.

Conclusion: The prediabetes prediction model can be used easily and understood by health-related users to assess prediabetes risk. The intervention program, designed based on our prediabetes model to prevent or delay the conversion of prediabetes to diabetes in the population. The discovery of pharmacological therapies to prevent further conversion is needed.

Keywords: Assess, Prediction, Prediabetes, Risk.

(C) 2017 The Authors. Published by Innovare Academic Sciences Pvt Ltd. This is an open access article under the CC BY license (http://creativecommons. org/licenses/by/4. 0/) DOI: http://dx.doi.org/10.22159/ajpcr.2017.v10i6.18215

\section{INTRODUCTION}

Diabetes mellitus is one of the common chronic diseases occurs in all countries. Indonesia is the world's fourth most populated country; it also has the seventh largest number of diabetic patients (7.6 million). Diabetes caused at least USD 548 billion dollars (11\% of the total health spending on adults worldwide) in 2013 [1]. Diabetes is a disease that recognized when it is too late to cure. In addition, there are some reasons that exacerbate the problem: The impact of diabetes on morbidity and mortality is well known [1-3]; the diagnosis was usually delayed around 4-7 years after disease onset largely due to the absence of symptoms during the early years [4], and $10-20 \%$ of persons with Type 2 diabetes are found to have developed cardiovascular complications by the date of diagnosis [5]. Indeed, this is why the promotion of healthy lifestyles and an early diagnosis constitutes a key strategic line of approach to this health problem [6].

Prediabetes is a high-risk condition for diabetes development and several other health outcomes later in life. For example, in 2012, 86 million Americans had prediabetes, putting them at 5-10\% per year and $50 \%$ lifetime cumulative risk for diabetes. Prediabetes was defined as impaired fasting glucose (fasting plasma glucose 100-125 mg/dL) impaired glucose tolerance (plasma glucose 140-199 mg/dL $2 \mathrm{hrs}$ after $75 \mathrm{~g}$ oral glucose load, known as oral glucose tolerance testing [OGTT]), or the combination of both conditions (which is called combined glucose intolerance) [7]. However, many individuals were unware that they were suffering from unknown diabetic or prediabetes or metabolic abnormalities, live with high plasma glucose levels for many years. Such levels may lead to establishment of tissue damage before classical signs and symptoms of this condition have become clinically established (polyuria, polydipsia, weight loss with or without polyphagia, and blurred vision) [8].
Diabetes affects approximately $10 \%$ of the world's adult population and is one of the leading risk factors for cardiovascular disease, renal failure, and visual impairment [3,9]. On the other hand, their evidence that changes in lifestyle can reduce or delay the appearance of diabetes in prediabetic individuals [10]. It is important to identify individuals with higher probability of presenting some glucose metabolism disorder and know the risk factors [6]. The prediction risk model is a practical and efficient tool to assess individual's prediabetes development status and screen out the target population at high risk. At present, there exist many diabetes risk score models that could be used to optimize the estimation of diabetes risk and make related intervention plans. However, the risk model for prediabetes is rather rare, whereas it is also a golden period to prevent diabetes. This study aimed to build a prediabetes risk score model based on population data. We anticipated that our prediabetes risk score model could help physicians to assess the progress of the conversion of prediabetes to diabetes and make related intervention plans to help patients prevent or delay the onset of diabetes. The secondary objective of the study was to find anthropometric characteristics that might be related to glucose intolerance among individuals. We hypothesized that a population would show a prevalence of prediabetes states of at least $20 \%$. We also hypothesized that demographic and anthropometric characteristics that might be related to glucose intolerance among individuals.

\section{METHODS}

\section{Study design and sample}

We conducted a cross-sectional study in which we analyzed data from a population at 16 districts at Palembang city, Indonesia during January until May 2016. There are Alang-Alang Lebar, Bukit Kecil, Gandus, Ilir Barat I, Ilir Barat II, Ilir Timur I, Ilir Timur II, Kalidoni, Kemuning, Kertapati, Plaju, Sako, Seberang Ulu I, Seberang Ulu II, Sematang Borang dan Sukarami. The study was approved by the 
government research committee of South Sumatera (protocol number 070/2354/BAN.KBP/2016). We recruited participants that had eligibility criteria for participants (inclusion and exclusion criteria). The study included 1241 participants that had aged $>15$ years and willing to do the examination a glucose tolerance test and physical examination weight, height, blood pressure, and waist circumference. And feature data to support on a variable risk of developing diabetes mellitus which was a history of hypertension, history of hypercholesterolemia, and family history with diabetics. All participant did not constitute exclusion criteria; there were previous diagnosis of diabetes mellitus or a prediabetic state, use of oral hypoglycemic agents or insulin, use of drugs that would interfere with glucose and insulin metabolism, such as angiotensin-converting enzyme inhibitors, angiotensin receptor blockers and thiazide diuretics, use of drugs that would interfere with the serum levels of high-density lipoprotein-cholesterol and triglycerides, and use of any pharmacological drugs to treat obesity.

\section{Testing procedures}

In the first phase, research team comes to home of the participant and give a standard questionnaire with information sheet and consent form. If participants agree, the next day examination was conducted. Data were collected through interviews using questionnaires, physical examinations with collection of anthropometric data and blood tests as described below.

\section{OGTT measurements}

Standard OGTT with a dose of 1.75 g glucose per kilogram of body weight (up to a maximum of $75 \mathrm{~g}$ ) after a 10 hrs overnight fast was done. OGTT was performed during standardized conditions. Participants were instructed to live as normal as possible in respect to diet and physical activity the days before the OGTT. The test was postponed to another day in the event of ongoing infection. They were also instructed not to exercise and to abstain from food, fluids (except water) and tobacco before the test. Prediabetes (fasting glucose $100-125 \mathrm{mg} / \mathrm{dl}$ equivalent to $5.6-6.9 \mathrm{mmol} / \mathrm{L}$ or $2 \mathrm{hrs}$ glucose $140-199 \mathrm{mg} / \mathrm{dl}$ equivalent to $7.8-11.0 \mathrm{mmol} / \mathrm{L}$ ) and diabetes (fasting glucose $\geq 126 \mathrm{mg} / \mathrm{dl}$ equivalent to $\geq 7.0 \mathrm{mmol} / \mathrm{L}$ or $2 \mathrm{hrs}$ glucose $\geq 200 \mathrm{mg} / \mathrm{dl}$ equivalent to $\geq 11.1 \mathrm{mmol} / \mathrm{L}$ ) was defined by glucose levels obtained during the OGTT according to the American Diabetes Association guidelines [11].

\section{Anthropometric measurements}

Anthropometric measurements - including height, weight, and waist circumferences - measured by the research team following standard protocols. Standing height is measured using a stadiometer bar, without shoes, with shoulders in a relaxed position and arms hanging freely, and recorded to the nearest $0.1 \mathrm{~cm}$. Body weight is measured when wearing light clothing with- out shoes on a digital electronic weighing scale (TD 150, range 4-150 kg). Body mass index (BMI) is then calculated as the weight $(\mathrm{kg})$ divided by height $\left(\mathrm{m}^{2}\right)$. BMI adapted from WHO were categorized as: Underweight (BMI <18.50), healthy weight $(18.50 \leq$ BMI $\leq 22.99)$, heavlyweight $(23.99 \leq \mathrm{BMI}$ $\leq 24.99)$, overweight $(25.0 \leq \mathrm{BMI} \leq 29.99)$, and obese (BMI $\geq 30$ ). Waist circumference is measured while the patients were standing, at the end of exhalation, at the midpoint between the lower costal border and the top of the iliac crest, using an inelastic tape in a horizontal position. Waist circumferences was categorized as: Very low risk (female: $<27.5 \mathrm{~cm}$; male: $<80 \mathrm{~cm}$ ), low risk (female: $70-89 \mathrm{~cm}$; male: $80-99 \mathrm{~cm}$ ), high risk (female: $90-109 \mathrm{~cm}$; male: $100-120 \mathrm{~cm}$ ), and very high risk (female: $>110 \mathrm{~cm}$; male: $>120 \mathrm{~cm}$ )

\section{Blood pressure measurements}

Blood pressure and pulse rate will also be taken to double check those written in medical records. They are measured twice in a sitting position after the participant has rested for at least 5 minutes. Measurements were taken 2 times on the right arm with short intervals between readings, and the average of blood pressure readings was calculated and used for analysis.

\section{Statistical analysis}

Statistical analyses were performed using the SPSS, version 22 . The statistical significance level was set at $\mathrm{p}<0.05$. Continuous variables were expressed as the mean \pm standard deviation for the variables with normal distribution. Categorical variables expressed as percentages. Differences between groups relating to categorical variables were determined using the Chi-square test and t-tests were used to compare means for continuous variables. We estimated the percentage of patients who presented each of these risk factors in the subjects with prediabetes and in the subjects without glucose metabolism disorders. The estimates were expressed in odds ratio and 95\% confidence intervals. The variables in the logistic regression model were screened out to build the risk score model.

\section{RESULTS}

A total of 1241 participant identified that prevalence prediabetes $(27.8 \%)$. Table 1 shows the prevalence of prediabetes for various demographic characteristics. A greater proportion of prediabetes group aged $>40$ years had significantly $(\mathrm{p}<0.005)$ when compared with the non-prediabetes group (Table 1). The percentage of prediabetes was significantly higher in the age group $>40$ years, married or with partner and unemployment $(\mathrm{p}<0.005)$.

Table 2 shows the change in prevalence of prediabetes was not significant for groups had a family history of diabetes and with smoking status $(p>0.005)$. The proportion of prediabetes was significantly higher in not routinely exercise group (30.5\%) and routinely exercise for groups with prediabetes was $19.5 \%$; the difference in proportion was statistically significant. The difference in BMI proportion was significant among prediabetes and without prediabetes group; the highest proportion was grouped with healthy weight and the smaller proportion was underweight group. A higher percentage of prediabetes group with history hypercholesterolemia $(90 \%)$ and was significant compared among the non prediabetes group. The mean of systolic blood pressure (mmHg) of prediabetes group was $129.79 \pm 17.70$ and mean of the non prediabetes group was $122.95 \pm 17.18$, and the difference was significant. The difference mean of diastolic blood pressure and sistolic blood pressure among prediabetes and nonprediabetes also significant $(\mathrm{p}<0.005)$.

Table 3 from multivariate analysis with binary regression logistic, we five variable as risk factor, that were employment, exercise, alcohol consumption, systolic pressure, and diastolic pressure. Moreover, four protective variables that were age, BMI, waist circumference and hypercholesterolemia history. The percent correct model to prediction prediabetes was $87.7 \%$.

Logit (Prediabet) $=-2.925-0.370$ (Age) +0.076 (employment $)+0.482$ (exersice) + 1.257 (alcohol consumption) -0.174 (BMI) + 0.0247 (systolic) +0.034 (diatolic) - (waist circumference) - 5.149 (hypercholesterol history).

\section{DISCUSSION}

The increase in the prevalence of diabetes associated with cardiovascular disease and the accompanying high morbidity and mortality make glucose perturbations a serious public health issue. Hence, early intervention in or prevention of prediabetes status should receive greater attention. In this study, we built a prediabetes risk score model that involves age, employment, exercise, alcohol consumption, BMI, diastolic blood pressure, systolic blood pressure, waist circumference, and hypercholesterol history of diabetes as risk factors. The risk factors used in our risk score model are consistent with the diabetes and prediabetes risk factors reported in previous literature $[8,12,13]$.

An interesting thing to consider was a family history of diabetes variable that's not significant to prediabetes group. These results were contrasted with findings from a population-based survey of civilian, non-institutionalized US and community-based populations in China, 
Table 1: General characteristics of the population studied among prediabetes and non-prediabetes

\begin{tabular}{|c|c|c|c|c|}
\hline \multirow[t]{2}{*}{ Characteristics } & \multirow{2}{*}{$\begin{array}{l}\text { Prediabetes (yes) } \\
n=345(27.8 \%)\end{array}$} & \multirow{2}{*}{$\begin{array}{l}\text { Prediabetes (no) } \\
\mathrm{n}=896(72.2 \%)\end{array}$} & \multirow{2}{*}{$\begin{array}{l}\text { Total } \\
n=1241\end{array}$} & \multirow[t]{2}{*}{ p value } \\
\hline & & & & \\
\hline \multicolumn{5}{|l|}{ Sex } \\
\hline Female & $180(27.2)$ & $481(72.8)$ & 661 & \\
\hline \multicolumn{5}{|l|}{ Age } \\
\hline$<40$ years & 119 (19.9) & $479(80.1)$ & 598 & $0.000^{*}$ \\
\hline$>40$ years & $226(35.1)$ & $417(64.9)$ & 643 & \\
\hline \multicolumn{5}{|l|}{ Marital status } \\
\hline Without partner & $62(20.9)$ & $235(79.1)$ & 297 & $0.003^{*}$ \\
\hline Married or with partner & $283(30.0)$ & $661(70.0)$ & 944 & \\
\hline \multicolumn{5}{|l|}{ Education } \\
\hline Primary & $42(28.4)$ & $106(71.6)$ & 148 & 0.726 \\
\hline Middle school & $179(28.6)$ & $446(71.4)$ & 625 & \\
\hline High school & $124(26.5)$ & $344(73.5)$ & 468 & \\
\hline \multicolumn{5}{|l|}{ Employment } \\
\hline Unemployment & $31(32.3)$ & $65(67.7)$ & 96 & $0.001^{*}$ \\
\hline Employees & $13(22.8)$ & $44(77.2)$ & 57 & \\
\hline Teacher & $29(25.4)$ & $85(74.6)$ & 114 & \\
\hline Freelance & $25(30.1)$ & 58 (69.9) & 83 & \\
\hline Trader & $10(9.7)$ & $93(90.3)$ & 103 & \\
\hline Student & $86(31.4)$ & $188(68.6)$ & 274 & \\
\hline Housewife & $10(29.5)$ & $25(70.5)$ & 359 & \\
\hline Others & 6 & 3 & & \\
\hline \multicolumn{5}{|l|}{ Race } \\
\hline Palembang & 201 (25.8) & $579(74.2)$ & 780 & 0.182 \\
\hline Jawa & $54(34.2)$ & $104(65.8)$ & 158 & \\
\hline Batak & $20(40.8)$ & $29(59.2)$ & 49 & \\
\hline Melayu & $28(25.0)$ & $84(75.0)$ & 112 & \\
\hline Ambon & $1(33.3)$ & $2(66.7)$ & 3 & \\
\hline Betawi & $2(40.0)$ & $3(60.0)$ & 5 & \\
\hline Sunda & $6(27.3)$ & $16(72.7)$ & 22 & \\
\hline Padang & 15 (24.2) & 47 (75.8) & 62 & \\
\hline Cina & $18(36.0)$ & $32(64.0)$ & 50 & \\
\hline
\end{tabular}

*Indicates the significance at the level $<0.05$

which also found that sibling history was a significant risk factor for diabetes $[14,15]$. Family history of diabetes may reflect the influence of both genetic and common environmental exposures shared within the family, therefore, knowledge of family history may be the first step toward determining the contribution of genetic and environmental factors in the development of diabetes [16]. In this study, it was possible because the group who has a family history of diabetes may have high levels of awareness of the risk factors of diabetes. Other variables must consider too was smoking, in this study, there was not significant to predict prediabetes. The underlying mechanism of cigarette smoking induced increased Type 2 diabetes is not entirely clear. Plausibility smoking was not directly related to blood glucose levels but might interact with body fat. Therefore, Zhang et al. study showed coexistence of current smoking and abdominal obesity contributes to the highest diabetes risk [17].

Screening in the prediabetes risk status has the best choice for prevention diabetes program, prediabetes has a golden period for prevent or delay the diabetes conversion. Recent data have confirmed the predisposition of subjects presenting with prediabetes to develop Type 2 diabetes. Patients presenting with normal glucose tolerance showed an $8 \%$ incidence of new-onset diabetes after 5 years, whereas $33 \%$ of individuals with impaired glucose tolerance developed Type 2 diabetes during the same time period [18]. Developing countries such as Indonesia also showed an increased prevalence of diabetes. Indonesia is the $4^{\text {th }}$ country with the largest population in the world and held the position of the $7^{\text {th }}$ country; most people with diabetes are 7.6 million people [19]. However, the detection rate of diabetes was still low, RISKESDAS Indonesia show in 2013, from $6.9 \%$ of diabetics, $30.4 \%$ had been diagnosed earlier, while $69.6 \%$ are not diagnosed previously.

Some evidence has shown that lifestyle modifications, as the cornerstone of diabetes prevention, could lead to a $40-70 \%$ relative-risk reduction [20]. Compared with interventions after the onset of diabetes, the related intervention measures started during the prediabetes stage are more efficient and sensible because they can prevent or delay the conversion from prediabetes to diabetes $[12,16]$.

The main limitation of this study was inherent in its cross-sectional design. It was not possible to determine cause and effect relationships, but rather, only associations could be reported. Another important limitation of this study was the fact that plasma hemoglobin A1c (HbA1c) assays were not performed on the research subjects, because when this study was planned and conducted, performing plasma HbA1c assays as a screening test for non-diabetic individuals was not part of the usual recommendations. Unfortunately, it was not possible to include $\mathrm{HbA1c}$ evaluations in this study consequent to that recommendation, because the blood of large samples was no longer stored. However, the main strength of this study is the focus on the prediabetes state

Furthermore, we have included a large number of participants from a population based. This study provides useful information when considering early detection of individuals with high risk of development diabetes and cardiovascular diseases. The detection of prediabetes in an individual should be accompanied by interventions addressing modifiable risk factors. The available evidence is still scarce; further studies are needed to check these findings and to confirm possible explanations, such as HbA1c and use cohort study with follow up. Intensive lifestyle changes and appropriate vitamin D supplementation may need to prevent or delay the prediabetes progression [21]. Vitamin D can improve insulin resistance and sensitivity and blood pressure regulations [22]. Pharmacological therapies also essentially 
Table 2: Risk factors, anthropometric characteristics of each group, and comparisons between groups

\begin{tabular}{|c|c|c|c|c|}
\hline \multirow[t]{2}{*}{ Variable } & \multirow{2}{*}{$\begin{array}{l}\text { Prediabetes (yes) } \\
n=345(27.8 \%)\end{array}$} & \multirow{2}{*}{$\begin{array}{l}\text { Prediabetes (no) } \\
n=896(72.2 \%)\end{array}$} & \multirow{2}{*}{$\begin{array}{l}\text { Total } \\
\mathrm{n}=\mathbf{1 2 4 1}\end{array}$} & \multirow[t]{2}{*}{ p value } \\
\hline & & & & \\
\hline \multicolumn{5}{|l|}{ Family history of diabetes } \\
\hline No & $227(27.2)$ & $609(72.8)$ & 836 & \\
\hline \multicolumn{5}{|l|}{ Exercise } \\
\hline Not routinely & $286(30.5)$ & $652(69.5)$ & 938 & 0.000 \\
\hline Routine & $59(19.5)$ & $244(80.5)$ & 303 & \\
\hline \multicolumn{5}{|l|}{ Alcohol consumption } \\
\hline Yes & $12(11.2)$ & 95 (88.8) & 107 & 0.003 \\
\hline No & $333(29.4)$ & $801(70.6)$ & 1134 & \\
\hline \multicolumn{5}{|l|}{ Smoking status } \\
\hline Active smoker & $69(24.6)$ & $212(75.4)$ & 281 & 0.319 \\
\hline Passive smoker & $89(27.6)$ & $234(72.4)$ & 323 & \\
\hline No smoking & $187(29.4)$ & $450(70.6)$ & 637 & \\
\hline \multicolumn{5}{|l|}{ BMI } \\
\hline Underweight & $15(23.8)$ & $48(76.2)$ & 63 & 0.000 \\
\hline Heavy weight & $80(29.5)$ & $191(70.5)$ & 271 & \\
\hline Overweight & 97 (38.5) & $155(61.5)$ & 252 & \\
\hline Obese & $28(30.4)$ & $64(69.6)$ & 92 & \\
\hline \multicolumn{5}{|l|}{ Waist circumference } \\
\hline Very low risk & 78 (19.9) & $313(80.1)$ & 391 & 0.000 \\
\hline Low risk & $203(28.2)$ & 517 (71.8) & 720 & \\
\hline High risk & $63(49.6)$ & $64(50.4)$ & 127 & \\
\hline Very high risk & $1(33.3)$ & $2(66.7)$ & 3 & \\
\hline \multicolumn{5}{|l|}{ Blood pressure } \\
\hline Systolic blood pressure (mmHg) & $129.79 \pm 17.70$ & $122.95 \pm 17.18$ & & 0.000 \\
\hline Diastolic blood pressure ( $\mathrm{mmHg}$ ) & $81.13 \pm 10.48$ & $78.10 \pm 10.19$ & & 0.000 \\
\hline \multicolumn{5}{|l|}{ Hypercholesterol history } \\
\hline Yes & $215(90.0)$ & $24(10.0)$ & 239 & 0.000 \\
\hline No & $130(13.0)$ & $872(87.0)$ & 1002 & \\
\hline
\end{tabular}

Table 3: Binary regression logistic model

\begin{tabular}{llll}
\hline Factors & Coefficients & p value & OR \\
\hline Age & -0.370 & $0.046^{*}$ & 0.690 \\
Employment & 0.076 & $0.017^{*}$ & 1.079 \\
Exercise & 0.482 & $0.037^{*}$ & 1.619 \\
Alcohol consumption & 1.257 & $0.007^{*}$ & 3.516 \\
BMI & -0.174 & $0.041^{*}$ & 0.840 \\
Systolic blood pressure (mmHg) & 0.027 & $0.002^{*}$ & 1.027 \\
Diastolic blood pressure (mmHg) & 0.034 & $0.007^{*}$ & 1.035 \\
Waist circumference & -0.405 & $0.007^{*}$ & 0.667 \\
Hypercholesterol history & -5.149 & $0.000^{*}$ & 0.006 \\
Constant & -2.925 & 0.001 & 0.054 \\
\hline *Indicates the significance at the level<0.05.
\end{tabular}

*Indicates the significance at the level<0.05. BMI: Body mass index

needed; one of that is pioglitazone. Pioglitazone is known to reduce risk of atherosclerosis in prediabetic and diabetic subjects. Pioglitazone is insulin sensitizer which improves and maintain long-term glycemic control along with its favorable cardiovascular effect especially macrovascular complications [23].

\section{CONCLUSION}

In the sample studied, the prevalence of prediabetes was $27.8 \%$. We found nine variables were screened out as independent factors to build the prediction risk model. Five variables as risk factors that were employed, exercise, alcohol consumption, systolic pressure, and diastolic pressure. Moreover, four protective variables that were age, BMI, waist circumference, and hypercholesterol history. The variables have been the modifiable risk factors independently related to the presence of prediabetes; just age has not modifiable risk factors. The discovery of pharmacological therapies to prevent further conversion of prediabetes to diabetes is needed.

\section{ACKNOWLEDGMENTS}

We would like thank to Indonesia Endowment Fund for Education (LPDP RI) for financing PhD scholarship and publishing this article. This work supported by Sriwijaya University, Medical Faculty of Sriwijaya University, Government of South Sumatera Province, Health Department of Palembang, Puskesmas staff for the support to conduct this research and our student Robby Akbar, Eugenia Jeniffer Jasmine, Leonardus Kolong, Sefani Gunawan, Cindy Kesty, and Lastri Ronauli Sitompul.

\section{REFERENCES}

1. Florencia A, Alex B, Ho CN, Gisela D, Sheree D, Trisha D, et al. IDF Diabetes Atlas. $6^{\text {th }}$ ed. Basel, Switzerland: International Diabetes Federation; 2013.

2. Jansson SP, Andersson DK, Svärdsudd K. Mortality trends in subjects with and without diabetes during 33 years of follow-up. Diabetes Care 2010;33:551-6.

3. Wermeling PR, Gorter KJ, van Stel HF, Rutten GE. Both cardiovascular and non-cardiovascular comorbidity are related to health status in well-controlled type 2 diabetes patients: A cross-sectional analysis. Cardiovasc Diabetol 2012;11:121.

4. Harris MI, Klein R, Welborn TA, Knuiman MW. Onset of NIDDM occurs at least 4-7 yearr before clinical diagnosis. J Diabetes Care $1992 ; 15(7): 815-9$

5. Medrano MJ, Pastor-Barriuso R, Boix R, del Barrio JL, Damián J, Alvarez R, et al. Coronary disease risk attributable to cardiovascular risk factors in the Spanish population. Rev Esp Cardiol 2007;60(12):1250-6.

6. Díaz-Redondo A, Giráldez-García C, Carrillo L, Serrano R, GarcíaSoidán FJ, Artola $\mathrm{S}$, et al. Modifiable risk factors associated with prediabetes in men and women: A cross-sectional analysis of the cohort study in primary health care on the evolution of patients with prediabetes (PREDAPS-Study). BMC Fam Pract 2015;16:5

7. Nathan DM, Davidson MB, DeFronzo RA, Heine RJ, Henry RR, Pratley R, et al. Impaired fasting glucose and impaired glucose tolerance: Implications for care. Diabetes Care 2007;30(3):753-9. 
8. Matos LN, Giorelli Gde V, Saado A, Dias CB. Prevalence of prediabetes in patients with metabolic risk. Sao Paulo Med J 2011;129(5):300-8.

9. Alberti KG, Zimmet P, Shaw J; IDF Epidemiology Task Force Consensus Group. The metabolic syndrome - A new worldwide definition. Lancet 2005;366(9491):1059-62.

10. Tuomilehto J, Lindström J, Eriksson JG, Valle TT, Hämäläinen H, Ilanne-Parikka $\mathrm{P}$, et al. Prevention of Type 2 diabetes mellitus by changes in lifestyle among subjects with impaired glucose tolerance. N Engl J Med 2001;344(8):1343-50.

11. American Diabetes Association. Diagnosis and classification of diabetes mellitus. Diabetes Care 2010;33 Suppl 1:S62-9.

12. Ouyang P, Guo X, Shen Y, Lu N, Ma C. A simple score model to assess prediabetes risk status based on the medical examination data. Can J Diabetes 2015;40(5):419-23.

13. Segura J, Roldán C, García-Donaire JA, Ruilope LM. Prediabetes and cardiovascular risk in hypertensive patients. Curr Hypertens Rep 2006;8(2):97-100

14. Annis AM, Caulder MS, Cook ML, Duquette D. Family history, diabetes, and other demographic and risk factors among participants of the National Health and Nutrition Examination Survey 1999-2002. Prev Chronic Dis J 2005;2(2):A19.

15. Chien KL, Hsu HC, Su TC, Chang WT, Chen PC, Chen MF, et al. Sibling and parental history in Type 2 diabetes risk among ethnic Chinese: The Chin-Shan community cardiovascular cohort study. Eur
J Cardiovasc Prev Rehabil 2008;15(6):657-62.

16. Zhang Y, Chen H, Lu H, Shen Y, Chen R, Fang P, et al. Prevalence and risk of diabetes based on family history in the Shanghai High-Risk Diabetic Screen (SHiDS) study. Diabet Med 2016;33(12):1705-11.

17. Zhang L, Guo Z, Wu M, Hu X, Xu Y, Zhou Z. Interaction of smoking and metabolic syndrome on cardiovascular risk in a Chinese cohort. Int J Cardiol 2003;167(1):250-3.

18. Agostino RB, Hamman RF, Karter AJ, Mykkanen L, Wagenknecht LE, Haffner SM. Cardiovascular disease risk factors predict the development of Type 2 diabetes: The insulin resistance atherosclerosis study.Diabetes Care J 2004;27(9):2234-40.

19. Ruhembe CC, Mosha TC, Nyaruhucha CN. Prevalence and awareness of Type 2 diabetes mellitus among adult population in Mwanza city, Tanzania. Tanzan. J Health Res 2014;16(2):1-11.

20. TabákAG, Herder C, Rathmann W, Brunner EJ, Kivimäki M. Prediabetes and the risk of diabetes - Authors' reply. Lancet 2012;380(9849):1226.

21. Venkates G, Jayprakash A, Swathi KS. The effect of sun light exposure on prediabetic patients in south indian population. Int J Pharm Pharm Sci 2014;6(11):107-10

22. DeLuca HF. Overview of general physiologic features and functions of vitamin D. Am J Clin Nutr 2004;80(6):1689-96.

23. Verma RK, Tripathi P, Pandey AK. Role of pioglitazone on progression of atherosclerosis in prediabetes: A mini review. Int J Pharm Pharm Sci 2014;6(2):13-5. 